\title{
PELAKSANAAN JAMINAN FIDUSIA PADA PEMBIAYAAN MURABAHAH DI BANK BNI SYARIAH KANTOR CABANG PROBOLINGGO
}

\author{
Sofian Syaiful Rizal, Insiyah \\ Universitas Nurul Jadid \\ E-mail: Sofiansyaifulrizal@gmail.com, Insiyah846@gmail.com
}

\begin{abstract}
The practice of implementing fiduciary guarantees on murabahah financing at Bank BNI Syariah provides legal certainty for Islamic banks as creditors. Given that many Islamic banks have implemented fiduciary guarantees as additional collateral for murabahah financing, the research method used is descriptive qualitative research. After the research process has been carried out, In practice, the fiduciary security must first be registered at the fiduciary security office, which Bank BNI Syariah represents to a notary. If there is a debtor default at Bank BNI Syariah, it will be resolved by sharia principles, namely by providing guidance and visits to the debtor. If there is still no good intention from the debtor to carry out their obligations then Bank BNI Syariah will execute objects bound by fiduciary by legal process. The conclusion is that the implementation of the fiduciary guarantee policy at the Bank BNI Syariah Probolinggo Branch Office must use a fiduciary binding as long as the murabahah object is a moving object.
\end{abstract}

Keywords : Murabahah, Fiduciary Guarantee, Islamic Banking

Abstrak: Praktek pelaksanaan jaminan fidusia pada pembiayaan murabahah di Bank BNI Syariah memberikan kepastian hukum bagi bank syariah sebagai kreditur. Mengingat sudah banyak bank syariah yang menerapkan jaminan fidusia sebagai jaminan tambahan pada pembiayaan murabahah.Adapun metode penelitian yang digunakan adalah penelitian deskriptif kualitatif. Pada pelaksanaannya, jaminan fidusia harus didaftarkan terlebih dahulu di kantor jaminan fidusia, yang mana Bank BNI Syariah mewakilkannya kepada notaris. Jika ada debitur yang melakukan wanprestasi di Bank BNI Syariah maka akan diselesaikan dengan prinsip-prinsip syariah yaitu dengan melakukan bimbingan dan kunjungan kepada debitur. Apabila tetap tidak ada niat baik dari debitur untuk melakukan kewajibannya, maka pihak Bank BNI Syariah akan melakukan eksekusi terhadap benda yang diikat dengan fidusia melalui proses hukum. Setelah diakukan proses penelitian, maka kesimpulannya adalah pelaksanaan kebijakan jaminan fidusia di Bank BNI Syariah Kantor Cabang Probolinggo wajib menggunakan pengikatan fidusia selama objek murabahah berupa benda bergerak.

Kata kunci : Murabahah, Jaminan Fidusia, Bank Syariah

\section{A. PENDAhULUAN}

Pembiayaan murabahah merupakan produk bank syariah yang berlandaskan prinsip jual beli. Menurut Dewan Syariah Nasional Majelis Ulama Indonesia (DSN-MUI) NO.04/DSN-MUI/IV/2000, murabahah ialah menjual barang dengan menyebutkan harga beli kepada pembeli, dan pembeli membayar kelebihan harga yang disepakati sebagai keuntungan. Menurut Yopie sebagai salah satu karyawan di Bank BNI Syariah Kantor Cabang Probolinggo, pembiayaan murabahah termasuk salah satu produk yang populer digunakan oleh lembaga keuangan syariah terutama perbankan syariah, untuk membiayai permintaan pembelian barangbarang konsumen yang dibutuhkan nasabah seperti mobil, motor, rumah, dan alat elektronik. 
Syarat mutlak untuk akad murababah yang sesuai syariah ialah bank harus melaksanakan akad murabahah yang bebas riba dan menolak pembiayaan yang diajukan nasabah apabila barang tersebut dilarang dan diharamkan oleh syariat islam. ${ }^{1}$

Pembiayaan murabahah merupakan fasilitas yang diberikan oleh Bank BNI Syariah guna memberikan pelayanan kepada nasabah. Murabahah diminati karena proses dan pelaksanaannya yang relative cepat dan mudah. Hal tersebut terlihat dari peningkatan pembiayaan tahunan dari laporan keuangan Bank BNI Syariah tahun 2019. Nasabah sebagai debitur mengajukan permohonan pembelian objek tertentu, apabila pihak bank setuju maka dengan waktu yang singkat debitur akan mendapatkan barang yang dibutuhkan tersebut.

Pada Praktiknya Bank menyediakan produk yang dibutuhkan kreditur melalui pembelian, bank kemudian menjualnya kembali dengan mennyebutkan harga beli dan keuntungan yang diminta bank. Untuk menjamin pembayaran piutang kepada bank, bank dapat meminta jaminan kepada nasabah sesuai dengan DSN-MUI No.04/DSN-MUI/IV/2000, jaminan dalam murabahah diperbolehkan, agar nasabah serius dan tidak lalai terhadap kewajibannya.

Suyatna sebagai pimpinan Bank BNI Syariah Kantor Cabang Probolinggo menjelaskan ada beberapa jaminan yang digunakan dalam pembiayaan murabahah seperti, surat kuasa membebankan hak tanggungan (SKMHT), akta pemberian hak tanggungan (APHT), sertifikat hak tanggungan(SHT), dan fidusia. Hak dan kewajiban bank bersifat timbal balik dengan nasabah. Hal ini tidak menjadi masalah jika bank dan nasabah saling memenuhi hak dan kewajiban. Biasanya akan terjadi permasalahan apabila debitur lalai dalam melaksanakan kewajiban yaitu pelunasan pinjamannya. Kondisi semacam ini membuat bank merasa tidak aman akan tidak kembalinya dana yang telah dikeluarkan bank. Oleh sebab itu ilmu hukum menerapkan jaminan dalam bentuk kebendaan. Ada beberapa jaminan yang berlaku dalam hukum substantive, salah satunya adalah jaminan fidusia. ${ }^{2}$

Jaminan fidusia memainkan peran penting dalam perlindungan hukum dan perlindungan kreditur. Pengikatan jaminan fidusia dilaksanakan secara notaris dengan tujuan supaya bank mempunyai kuasa penuh secara legalitas atas benda yang dijaminkan nasabah. Pengikatan fidusia tidak hanya menguntungkan kreditur, tetapi juga memungkinkan debitur untuk menggunakan objek yang dijaminkan.

Hasil studi Halimatus Sadiyah menunjukkan, bahwa pembiayaan murabahah lebih kecil resikonya dibanding dengan pembiayaan bank syariah lainnya, sehingga terjadi peningkatan pembiayaan murabahah yang menggunakan jaminan fidusia. ${ }^{3}$

Dari temuan Ratna Fitri Andin di BPR Mandiri Mitra Sukses Gresik menyatakan jaminan fidusia merupakan suatu perjanjian yang ditambahkan dalam akad murabahah. Jika

${ }^{1}$ Raden Andriana Meirani, Ahmad Damiri, and Jalaludin Jalaludin, "Penerapan Akad Murabahah Pada Produk MULIA Di Pegadaian Jalancagak Menurut Perspektif Ekonomi Syariah," EKSISBANK (Ekonomi Syariah dan Bisnis Perbankan) 4, No. 1 (2020).hlm. 60-68.

${ }^{2}$ Pamungkas, Suyatna Putra, interview by Insiyah. Pelaksanaan Jaminan Fidusia pada Pembiayaan Murabahah di Bank BNI Syariah Probolinggo (November 20, 2020).

${ }^{3}$ Halimatus Sadiyah, "Kedudukan Fidusia Sebagai Jaminan Akad Pembiayaan Murabahah Pada Bank Syariah: Studi Kasus Pada Bprs Bhakti Sumekar Sumenep,” Misykat Al-Anwar 29, No. 2 (2018). 
nasabah gagal memenuhi kewajibannya, BPR Syariah Mandiri Mitra Sukses Gresik menyelesaikannya terlebih dahulu melalui jalur kekerabatan, abitrase syariah, dan terakhir proses peradilan. ${ }^{4}$

Dari hasil penelitian Anggraeni Yani menyimpulkan, pelaksanaan eksekusi jaminan fidusia di BPRS Khasanah Ummat Purwokerto dilakukan negosiasi dengan nasabah, apabila negosiasi tidak ada hasil maka akan dilakukan titel eksekutorial. ${ }^{5}$ Jatmiko Menyatakan bahwa perlindungan hukum kreditur untuk jaminan fidusia membutuhkan pembentukan lembaga penegak hukum dan kebutuhan konseling secara berkala tentang jaminan fidusia. ${ }^{6}$

Mengingat banyaknya bank syariah yang membutuhkan jaminan fidusia untuk pembiayaan murabahah, maka sangat menarik dan penting untuk dikaji lebih dalam lagi bagaimana penerapan jaminan fidusia untuk pembiayaan murabahah di bank syariah dan bagaimana jaminan fidusia dapat memberikan perlindungan hukum kepada kreditur.

Tujuan penelitian ini adalah untuk mengetahui dan menganalisis secara parsial bagaimana pelaksanaan dan penerapan jaminan fidusia dalam pembiayaan murabahah pada Bank BNI Syariah dan serta bagaimana jaminan fidusia dapat memberikan perlindungan dan jaminan hukum kepada bank syariah sebagai kreditur.

\section{B. METODE PENELITIAN}

Dalam penelitian ini, penulis menggunakan metode penelitian kualitatif deskriptif untuk mendeskripsikan suatu peristiwa yang saat ini berlaku, dengan kata lain penelitian ini tidak mencari tahu dan menjelaskan hubungan, akan tetapi penelitian ini berbentuk narasi yang bertujuan untuk mengumpulkan informasi aktual secara rinci yang menjelaskan tentang pelaksanaan jaminan fidusia pada pembiayaan murabahah di Bank BNI Syariah Kantor Cabang Probolinggo. Adapun bahan yang digunakan berupa data primer, yaitu data yang secara langsung diperoleh dari pihak Bank BNI Syariah Kantor Cabang Probolinggo. Data tersebut diperoleh dari wawancara langsung dengan staf Bank BNI Syariah Kantor Cabang Probolinggo. Serta data sekunder yang didapat dari UndangUndang Jaminan Fidusia No.42 Tahun 1999, dan perundangan lainnya.Serta data sekunder lainnya yaitu bahan acuan seperti buku dan artikel yang membahas tentang pembiayaan murabahah dan jaminan fidusia.

${ }^{4}$ Ratna Fitri Andini, "Implementasi Jaminan Fidusia Atas Pembiayaan Murabahah Di Bpr (Bank Pembiayaan Rakyat) Syariah Mandiri Mitra Sukses Gresik," MAQASID, 5, No. 2 (2018), hlm. 1-12.

${ }^{5}$ Anggraeni Yani, "Pelaksanaan Eksekusi Jaminan Fidusia Dalam Pembiayaan Murabahah Di Bprs Khasanah Ummat Purwokerto Pasca Putusan Mahkamah Konstitusi Nomor 18/Puu-Xvii/2019” (IAIN Purwokerto, 2020).

${ }^{6}$ Jatmiko Winarno, "Perlindungan Hukum Bagi Kreditur Pada Perjanjian Jaminan Fidusia,” Jurnal Independent 1, no. 1 (2013).hlm. 44-55. 


\section{HASIL DAN PEMBAHASAN}

\section{Informasi Umum Bank BNI Syariah}

Bank BNI Syariah merupakan hasil penambahan dari Unit Usaha Syariah (UUS) PT Bank Negara Indonesia yang telah beroperasi sejak 29 April 2000. Proses penambahan uasaha berlandaskan terbitnya UU No.21 Tahun 2008 tentang perbankan syariah.

BNI Syariah secara resmi beroperasi pada 19 Juni 2010 setelah mendapat surat keputusan Gubernur Bank Indonesia NO.12/41/KEP.GBI/2010 tanggal 21 Mei 2010. Bank BNI Syariah mengusung visi dan misi sebagai berikut:

Visi: Menjadi Bank Syariah Pilihan Masyarakat yang Unggul dalam Layanan dan Kinerja. Misi:

a. Memberikan kontribusi positif kepada masyarakat serta peduli pada kelestarian lingkungan

b. Memberikan solusi bagi masyarakat untuk kebutuhan jasa perbankan syariah

c. Memberikan nilai investasi yang optimal bagi investor

d. Mencipatakan wahana terbaik sebagai tempat kebanggaan untuk berkarya dan berprestasi bagi pegawai sebagai perwujudan ibadah

e. Menjadi acuan tata kelola perusahaan yang amanah. ${ }^{7}$

\section{Pelaksanaan Jaminan Fidusia Pada Pembiayaan Murabahah Di Bank BNI Syariah} Probolinggo

Ada dua jenis murabahah yang dibiayai, yaitu murabahah yang objeknya bergerak dan tidak bergerak. Murabahah yang objek barangnya tidak bergerak seperti pembelian rumah, pembelian tanah, dan lainnya menggunakan pengikatan berupa hak tanggungan. Sedangkan untuk murabahah yang objeknya bergerak akan menggunakan pengikatan fidusia.

Dalam pembiayaan murabahah, tidak ada ketentuan nominal dari Bank BNI Syariah. Bank BNI Syariah mewajibkan menggunakan ikatan tambahan yaitu fidusia selama objek murabahah berupa benda bergerak.Bank BNI Syariah Kantor Cabang Probolinggo mengharuskan penggunaan jaminan fidusia ialah untuk memberikan perlindungan yang sah secara hukum serta nasabah bersungguh-sungguh dalam melunasi kewajibannya.Yopie menjelaskan dalam pelaksanaannya ada beberapa langkah dalam pemberian pembiayaan murabahah di Bank BNI Syariah, yaitu sebagai berikut:

a. Permohonan Pembiayaan

Untuk mekanisme permohonan pembiayaan, debitur mengisi formulir informasi pribadi yang disediakan oleh Bank BNI Syariah secara lengkap meliputi nama lengkap, alamat, tempat tanggal lahir, pekerjaan, dan jenis kelamin. Tujuan pengisian formulir adalah agar bank dapat mengetahui secara lengkap identitas debitur dan barang yang diinginkan oleh debitur. Setelah debitur mengisi formulir, bank akan memproses lebih lanjut data yang diberikan debitur.

\footnotetext{
7"Visi \& Misi | BNI Syariah," accessed November 12, 2020, https://www.bnisyariah.co.id/id$\mathrm{id} /$ perusahaan/tentangbnisyariah/visimisi.
} 


\section{b. Analisa Kredit}

Selanjutnya bank akan menganalisa calon debitur serta objek barang yang diminta. Tujuannya ialah untuk mengetahui kelengkapan persyaratan debitur dan kelayakan debitur.Dalam menganalisa calon debitur, Bank BNI Syariah berprinsip pada 5C, yaitu character, capital, capacity, collateral, dan condition.

c. Pemberian keputusan dan perjanjian akad murabahah

Ditahap ini, Bank akan mengeluarkan persetujuan secara tertulis yang berisi pernyataan bank setuju dan bersedia untuk menyediakan objek barang yang diminta debitur. Setelah diberikan surat persetujuan, dengan syarat, bank membeli barangnya terlebih dahulu atau bank mewakilkannya kepada nasabah. Kemudian bank menjualnya kepada nasabah, barang adalah objek jual beli yang harus jelas secara kualitas, kuantitas, spesifikasi, dan harga perolehan.Yang selanjutnya bank dan nasabah diijab qabul dengan akad muarabah.

d. Pembuatan dan Pendaftaran akta Jaminan fidusia

Setelah perjanjian murabahah, tahap selanjutnya adalah debitur dan kreditur membuat perjanjian pengikatan jaminan fidusia dengan akta notaris. Prasetya Mengatakan, kantor wilayah hukum dan HAM tidak menerima akta bawah tangan.Sehingga debitur harus menggunakan akta sah dari notaris ketika melakukan pendaftaran akta jaminan fidusia. ${ }^{8}$

Tahap selanjutnya pendaftaran akta jaminan fidusia pada kantor pendaftaran fidusia yang berada di bawah kementerian kehakiman. Pada pelaksanaannya registrasi jaminan fidusia dilakukan oleh penerima fidusia yaitu pihak bank yang melalui kuasa kepada notaris. Hal ini dijelaskan dalam Pasal 13 ayat UU Fidusia, registrasi jaminan fidusia dilakukan oleh penerima fidusia.

Suyatna sebagai pimpinan di Bank BNI Syariah Kantor Cabang Probolinggo Menjelaskan, untuk pendaftaran jaminan pihak Bank BNI Syariah memberikan wewenang kepada notaris untuk melaksanakan proses registrasi jaminan fidusia. ${ }^{9}$

Safitri sebagai notaris yang diberi kuasa oleh pimpinan dalam pembuatan akta jaminan fidusia di Bank BNI Syariah Kantor Cabang Probolinggo menjelaskan, dalam akta jaminan fidusia notaris harus melengkapi semua berkas permohonan pendaftaran yang memuat data sebagaimana berikut:

a. Informasi pribadi pemberi dan penerima fidusia

b. Tanggal, nomor akta jaminan fidusia, identitas dan tempat kedudukan notaris pembuat akta

c. Data perjanjian yang menjadi pokok utama dalam jaminan fidusia

d. Keterangan mengenai objeek jaminan fidusia

e. Nilai jaminan

\footnotetext{
${ }^{8}$ Treesna Prasetya and M Jafar, “Akibat Hukum Pelanggaran Ketentuan Dalam Pendaftaran Sertifikat Jaminan Fidusia,” IUS (kajian Hukum dan Keadilan) 7, No. 3 (2019), hlm. 496-505.

${ }^{9}$ Pamungkas, Suyatna Putra, interview by Insiyah. Pelaksanaan Jaminan Fidusia pada Pembiayaan Murabahah di Bank BNI Syariah Probolinggo (November 20, 2020).
} 
f. Nilai objek yang digunakan dalam jaminan. ${ }^{10}$

Ayu Sukihana Mengatakan, dengan adanya akta jamina fidusia pihak yang bersangktan telah terikat, hal ini termasuk bagian urgent dalam pengikatan dengan jaminan fidusia. $^{11}$

Ferdelina Menjelaskan, akta yang memilki kekuatan penuh adalah akta asli dari notaris, mengingat benda yang difidusiakan adalah benda bergerak yang belum terdaftar. Selanjutnya akta tersebut didaftarkan ke kantor pendaftran untuk disahkan dan mendapat sertifikat fidusia. ${ }^{12}$

Setelah mengajukan pendaftaran akta fidusia, kantor pendaftaran fidusia akan mencatatnya dalam buku pendaftaran. Kemudian bank akan menerima bukti pendaftaran. Selanjutnya debitur membayar biaya pendaftaran yang sudah termasuk dalam biaya administrasi murabahah.

Pendaftaran dapat dilakukan secara online dan ditandatangani secara elektronik. Setelah pendaftaran fidusia dilakukan, kantor pendaftaran fidusia mengeluarkan sertifikat fidusia dan menyerahkannya kepada bank selaku penerima fidusia.

\section{Eksekusi Jaminan Fidusia}

Dengan didaftarkannya jaminan fidusia dan mendapat sertifikat fidusia, pihak yang bersangkutan sama-sama diuntungkan. Yaitu bank tetap mempunyai kuasa penuh atas benda yang dipakai oleh nasabah. Karena dengan adanya sertifikat fidusia pihak yang saling terikat dilindungi penuh oleh hukum untuk menghindari resiko yang sewaktu-waktu dapat terjadi.

Faridy Mengatakan, Penggunaan jasa debt collector masih sering terjadi pada pelaksanaan eksekusi di lapangan yang kadang dilakukan saat benda atau kendraan tersebut sedang dipakai, hal ini yang memberikan dampak negatif seperti bantahan dan perlawanan dari debitur. ${ }^{13}$

Untuk eksekusi yang kondusif dan aman, telah diterbitkan peraturan kepala kepolisian Republik Indonesia No. 8 Tahun 2011. Untuk eksekusi jaminan fidusia yang kondusif, aman, tertib, serta dapat dipertanggung jawabkan, melindungi para pihak, dan mengindari kerugian. Maka bank harus mengeluarkan surat tertulis untuk melakukan eksekusi. jika eksekusi diwakilkan, maka harus menyertakan bukti surat kuasa yang sah dari kepolisian. $^{14}$

Adapun persyaratan untuk melaksanakan eksekusi adalah:

a. Adanya permintaan eksekusi dari pemohon

b. Objek yang akan dieksekusi memiliki akta dan sertifikat fidusia

\footnotetext{
${ }^{10}$ Safitri Kusumawardani, interview by Insiyah. Pelaksanaan Jaminan Fidusia pada Pembiayaan Murabahah di Bank BNI Syariah Probolinggo (November 28, 2020).

${ }^{11} \mathrm{Ni}$ Wayan Indah Junyanitha I Nyoman Mudana Ida Ayu Sukihana, "Pendaftaran Fidusia Dalam Praktek Pemberian Kredit Pada Pt. Bank Perkreditan Rakyat Raga Jayatama Di Batubulan Gianyar," Kertha Semaya 3, No. 2 (2015), hlm. 1-5.

${ }^{12}$ Fince Ferdelina Huru, "Kedudukan Hukum Akta Jaminan Fidusia Yang Tidak Didaftarkan," JURTAMA 1, no. 1 (2019), hlm. 46-57.

${ }^{13}$ Faridy, "Problematika Penbebanan Jaminan Fidusia," HAKAM: Jurnal Kajian Hukum Islam dan Hukum Ekonomi Islam 1, No. 2 (2017).

${ }^{14}$ Febrian Hadi, "Perjanjian Jaminan Fidusia (Studi Terhadap Jaminan Fidusia Yang Tidak Didaftarkan)," Journal of Chemical Information and Modeling 53, No. 9 (2019). hlm, 86-99.
} 
c. Berada di Indonesia.

Erni hastutik seorang pedagang menyampaikan, pembiayaan murabahah yang diikat dengan fidusia memberikan rasa aman untuk dirinya karena tidak akan terjadi penyitaan barang jaminan dengan menggunakan kekerasan serta penyitaaan harus menyertakan bukti permintaan penyitaan jaminan tertulis yang sah dari kepolisian. ${ }^{15}$

Yopie mengatakan, eksekusi di Bank BNI Syariah Kantor Cabang Probolinggo sangat jarang terjadi karena bank terlebih dahulu menempuh jalur kekeluargaan jika ada debitur yang melakukan wanprestasi. Dan sebelum melakukan pembiayaan, Bank BNI Syariah telah melakukan analisis kepada nasabah secara menyeluruh seperti yang dijelaskan di atas ${ }^{16}$.

\section{Jaminan Fidusia Sebagai Perlindungan Hukum Bagi Kreditur}

Salim dalam bukunya mengatakan, pendaftaran jaminan fidusia ialah untuk melindungi secara hukum pihak yang berkepentingan, dan memberikan kepastian pada hak yang didahulukan dari kreditur lainnya. Dan penerima fidusia tetap menguasi benda yang telah dialihkan kepemilikannya. ${ }^{17}$

Dengan tidak dikukuhkannya akta fidusia menjadi sertifikat fidusia, Selain tidak memiliki hak didahulukan dari kreditur lainnya, kreditur juga tidak memiliki hak eksekutorial terhadap benda yang dijadikan jaminan apabila sewaktu-waktu benda tersebut harus dieksekusi. ${ }^{18}$

Perlindungan hukum dan kepentingan kreditur dalam Undang-Undang Jaminan Fidusia yang dapat dilihat pada pasal 20 Undang-Undang Jaminan Fidusia yang berbunyi Fidusia tetap mengikuti benda yang menjadi objek jaminan fidusia dalam tangan siapa saja benda tersebut berada, kecuali pengalihan atas benda tersebut, kecuali pengalihan atas benda persediaan yang dijadikan objek jaminan fidusia. ${ }^{19}$ Dijelaskan oleh pasal 23 ayat (2) yang berbunyi Pemberi fidusia dilarang menggadaikan, mengalihkan, dan menyewakan kepada pihak lain benda yang menjadi objek jaminan fidusia dan tidak merupakan benda persediaan, kecuali dengan persetujuan tertulis terlebih dahulu dari penerima fidusia. ${ }^{20}$

Adapun sanksi terhadap debitur yang melakukan pelanggaran maka bisa dipidana sesuai dengan pasal 35 dan 36 undang-undang jaminan fidusia yang berbunyi:

"Setiap orang yang sengaja memalsukan, mengubah, menghilangkan atau dengan cara apapun memberikan keterangan secara menyesatkan, yang jika menyesatkan, jika hal tersebut diketahui oleh salah satu pihak tidak melahirkan perjanjian jaminan fidusia, dipidana dengan penjara paling singkat 1 (satu) tahun dan paling lama 5 (lima) tahun dan

\footnotetext{
${ }^{15}$ Erni Hastutik, interview by Insiyah. Pelaksanaan Jaminan Fidusia pada Pembiayaan Murabahah di Bank BNI Syariah Probolinggo (November 29, 2020).

${ }^{16}$ Yuarsyah, Yopi Rama, interview by Insiyah. Pelaksanaan Jaminan Fidusia pada Pembiayaan Murabahah di Bank BNI Syariah Probolinggo (November 16, 2020).

${ }^{17} \mathrm{H}$ S Salim, Perkembangan Hukum Jaminan Di Indonesia (Divisi Buku Perguruan, PT RajaGrafindo Persada, 2014), hlm. 27.

${ }^{18}$ Kadek Cinthya Dwi Lestari, I Nyoman Putu Budiartha, and Ni Made Puspasutari Ujianti, "Hilangnya Objek Jaminan Fidusia Yang Tidak Didaftarkan," Jurnal Analogi Hukum 2, No. 3 (2020), hlm. 383-387.

${ }^{19} \mathrm{Ni}$ Putu Theresa Putri Nusantara, "Eksekusi Dan Pendaftaran Objek Jaminan Fidusia Berdasarkan Undang - Undang Nomor 42 Tahun 1999 Tentang Jaminan Fidusia,” Jurnal Fakultas Hukum Universitas Udayana 2 , no. 2 (2018), hlm. 10.

${ }^{20}$ Ibid.
} 
denda paling sedikit Rp. 10.000.000.- (sepuluh juta rupiah) dan paling banyak Rp. 100.000.000.- (seratus juta rupiah)"

"Pemberi fidusia yang mengalihkan, menggadaikan, atau menyewakan benda yang menjadi objek jaminan fidusia sebagaimana dimaksud dalam pasa 23 ayat (2) yang dilakukan tanpa persetujuan tertulis terlebih dahulu dari penerima fidusia, dipidana dengan pidana penjara paling lama 2 (dua) tahun dan denda paling banyak Rp. 50.000.000. - (lima puluh juta juta rupiah). ${ }^{21}$

Perjanjian jaminan fidusia, pada pokoknya antara debitur dan kreditur sama-sama memiliki tanggung jawab terhadap keadaan dari setiap kehilangan, kehancuran, kemusnahan, kemunduran, pengurangan kualitas dan kerusakan benda jaminan. Apabila terjadi kerusakan padabenda yang dijaminkan, maka debitur harus mengganti. Pertanggungjawaban utang tersebut ialah meletakkan tuntutan pengadilan atas benda yang difidusiakan dan kemudian akan dijual menurut ketentuan hukum jaminan. Apabila agunan jaminan fidusia dalam keadaan rusak, dan debitur fidusia tidak dapat melunasi utangnya, Kelalaian atas kewajiban menjaga serta merawat benda jaminan fidusia adalah tanggung jawab debitur. ${ }^{22}$

Dengan adanya akta sah dari notaris dan sertifikat fidusia dapat memperkuat Bank Syariah atas benda yang dijaminkan yaitu nasabah penerima pembiayaan tidak boleh menjual barang-barang yang pembeliaannya oleh pihak bank dan benda-benda lain yang dijaminkan sampai utangnya lunas, sehingga jika nasabah penerima pembiayaan melanggar, maka bank dapat menggugat nasabah ke pengadilan dengan dasar wanprestasi. Wanprestasi terjadi apabila nasabah peminjam dana tidak menepati dengan tenggat waktu yang ditentukan oleh bank, dengan adanya pelanggaran ini bank dapat melakukan eksekusi dengan cara menjual atau melelangnya. ${ }^{23}$

Selama pengikatan fidusia berlangsung, Bank BNI Syariah memegang hak milik benda sebagai jaminan. Apabila debitur sudah membayar lunas hutangnya maka hak milik benda jaminan akan beralih kepada debitur. Debitur wajib menjaga objek jaminan selama pengikatan masih berlangsung. ${ }^{24}$

Yopie sebagai salah satu karyawan di Bank BNI Syariah Kantor Cabang Probolinggo Menjelaskan, untuk memastikan barang yang menjadi objek murabahah tetap aman dan tidak terjadi hal yang diinginkan, Bank BNI Syariah kantor Cabang Probolinggo bekerja sama dengan jasa asuransi syariah dan mengasuransikan benda untuk mengantisipasi adanya kerugian yang disebabkan oleh kelalaian nasabah dalam menjaga benda yang dijaminkan.

Adapun dalam hal melaksanakan kewajiban pembayaran, jika ada debitur yang melakukan wanprestasi maka jalan yang ditempuh oleh Bank BNI Syariah Kantor Cabang

${ }^{21}$ Ibid.

${ }^{22}$ Daniel Romi Sihombing, "Perlindungan Hukum Bagi Debitur Wanprestasi Dalam Eksekusi Jaminan Fidusia Berdasarkan Undang-Undang Nomor 42 Tahun 1999 Tentang Fidusia," Jurnal Hukum Media Justitia Nusantara 6, No. 1 (2019), hlm. 38.

${ }^{23} \mathrm{Ibid}$.

${ }^{24}$ Muhammad Kausar, "Pemberian Kredit Dengan Jaminan Fidusia Yang Tidak Didaftarkan,” Jurnal Ilmiah Mahasiswa Bidang Hukum Keperdataan 1, No. 1 (2017), hlm. 138-151. 
Probolinggo yang pertama adalah penyelesaian dengan cara kekeluargaan dengan prinsip syariah yaitu melakukan bimbingan serta kunjungan kepada debitur seperti diarahkan menjual objek jaminan jika memang debitur tidak sangup lagi membayar hutangnya. Apabila tetap tidak ada niat baik dari debitur untuk membayarnya maka Bank BNI Syariah akan melakukan tindak tegas terhadap benda yang dijaminkan dengan proses hukum dan peradilan.

Tangguh Hendrawan seorang karyawan swasta dan salah satu nasabah yang melakukan pembiayaan murabahah mengatakan, pihak bank akan melakukan kunjungan apabila ada keterlambatan dalam melaksanakan pembayaran setiap bulannya. Pihak bank tetap melakukan bimbingan agar nasabah tepat waktu dalam melaksanakan kewajibannya. ${ }^{25}$

Inilah pentingnya didaftarkannya jaminan fidusia yaitu bank mempunyai kuasa penuh secara legalitas dan jika debitur Melakukan wanprestasi maka benda jaminan murabahah dapat dieksekusi dan sah secara hukum. Dalam pelaksanaan eksekusinya, apabila bank telah meminta objek jaminan terhadap debitur karena adanya wanprestasi, maka debitur harus menyerahkan benda tersebut dengan kondisi baik dan terpelihara. Apabila tidak diserahkan oleh dengan jangka waktu yang telah ditentukan, bank dapat meminta bantuan dari pihak berwajib untuk mengeksekusi benda yang menjadi jaminan murabahah, yang hal ini tidak lah dilarang oleh UU No. 42 Tahun 1999.Dan bank wajib mengembalikan sisa penjualan jika barang yang terjual melebihi sisa jumlah hutang nasabah.Sebaliknya apabila hasil penjualan benda jaminan tidak mencukupi maka nasabah tetap terikat dan bertanggung jawab atas hutangnya. ${ }^{26}$

\section{KESIMPULAN}

Dalam pembiayaan murabahah, tidak ada ketentuan nominal dari Bank BNI Syariah. Bank BNI Syariah mewajibkan menggunakan pengikatan fidusia selama objek murabahah berupa benda bergerak. Pada pelaksanaannya, jaminan fidusia harus didaftarkan, yang mana Bank BNI Syariah mewakilkannya kepada notaris.jaminan fidusia sebagai pengikat tambahan agar debitur tidak lalai dalam menjalankan kewajibannnya dan menjaga dengan baik objek yang difidusiakan. Pendaftaran jaminan fidusia bertujuan supaya Bank BNI Syariah sebagai kreditur dan penerima fidusia mempunyai kuasa penuh secara legalitas atas jaminan nasabah yang diagunkan. Serta jaminan fidusia memberikan kemudahan bagi debitur, selain memperoleh pembiayaan, debitur dapat menggunakan benda yang telah dijaminkan. Jika ada yang debitur yang melakukan wanprestasi, Bank BNI Syariah Kantor Cabang Probolinggo akan terlebih dahulu menyelesaikan secara kekeluargaan dengan prinsip syariah yaitu dengan melakukan bimbingan serta kunjungan kepada debitur. Dan apabila tetap tidak ada niat baik dari debitur untuk melakukan kewajibannya, maka pihak Bank BNI Syariah akan melakukan eksekusi kepada benda yang dijamin dengan fidusia melalui proses hukum.

\footnotetext{
${ }^{25}$ Tangguh Hendrawan, interview by Insiyah. Pelaksanaan Jaminan Fidusia pada Pembiayaan Murabahah di Bank BNI Syariah Probolinggo (November 29, 2020).

${ }^{26}$ Dofi Yos Hermawan, "Implikasi Hukum Pendaftaran Jaminan Fidusia Online Terhadap Asas Publisitas Sebagai Salah Satu Ciri Hak Jaminan Kebendaan," Jurnal Media Hukum dan Peradilan 5, No. 1 (2019),hlm. 79-87.
} 


\section{E. DAFTAR PUSTAKA}

Andini, Ratna Fitri. "Implementasi Jaminan Fidusia Atas Pembiayaan Murabahah Di BPR (Bank Pembiayaan Rakyat) Syariah Mandiri Mitra Sukses Gresik." MAQASID, 2018.

Erni Hastutik, interview by Insiyah. Pelaksanaan Jaminan Fidusia pada Pembiayaan Murabahah di Bank BNI Syariah Probolinggo (November 29, 2020).

Faridy, Faridy. "Problematika Penbebanan Jaminan Fidusia." HAKAM: Jurnal Kajian Hukum Islam dan Hukum Ekonomi Islam 1, no. 2 (2017).

Febrian Hadi. "Perjanjian Jaminan Fidusia (Studi Terhadap Jaminan Fidusia Yang Tidak Didaftarkan)." Journal of Chemical Information and Modeling 53, no. 9 (2019).

Hermawan, Dofi Yos. "Implikasi Hukum Pendaftaran Jaminan Fidusia Online Terhadap Asas Publisitas Sebagai Salah Satu Ciri Hak Jaminan Kebendaan.” Jurnal Media Hukum dan Peradilan 5, no. 1 (2019).

Huru, Fince Ferdelina. "Kedudukan Hukum Akta Jaminan Fidusia Yang Tidak Didaftarkan." JURTAMA 1, no. 1 (2019).

Kausar, Muhammad. "Pemberian Kredit Dengan Jaminan Fidusia Yang Tidak Didaftarkan." Jurnal Ilmiah Mahasiswa Bidang Hukum Keperdataan 1, no. 1 (2017).

Lestari, Kadek Cinthya Dwi, I Nyoman Putu Budiartha, and Ni Made Puspasutari Ujianti. "Hilangnya Objek Jaminan Fidusia Yang Tidak Didaftarkan." Jurnal Analogi Hukum 2, no. 3 (2020).

Meirani, Raden Andriana, Ahmad Damiri, and Jalaludin Jalaludin. "Penerapan Akad Murabahah Pada Produk MULIA Di Pegadaian Jalancagak Menurut Perspektif Ekonomi Syariah.” EKSISBANK (Ekonomi Syariah dan Bisnis Perbankan) 4, no. 1 (2020).

Nusantara, Ni Putu Theresa Putri. "Eksekusi Dan Pendaftaran Objek Jaminan Fidusia Berdasarkan Undang - Undang Nomor 42 Tahun 1999 Tentang Jaminan Fidusia." Jurnal Fakultas Hukum Universitas Udayana 2, no. 2 (2018).

Prasetya, Treesna, and M Jafar. "Akibat Hukum Pelanggaran Ketentuan Dalam Pendaftaran Sertifikat Jaminan Fidusia." IUS (kajian Hukum dan Keadilan) 7, no. 3 (2019).

Pamungkas, Suyatna Putra, interview by Insiyah. Pelaksanaan Jaminan Fidusia pada Pembiayaan Murabahah di Bank BNI Syariah Probolinggo (November 20, 2020)

Sadiyah, Halimatus. "Kedudukan Fidusia Sebagai Jaminan Akad Pembiayaan Murabahah Pada Bank Syariah: Studi Kasus Pada Bprs Bhakti Sumekar Sumenep.” Misykat Al-Anwar 29, no. 2 (2018).

Salim, H S. Perkembangan Hukum Jaminan Di Indonesia. Divisi Buku Perguruan, PT RajaGrafindo Persada, 2014.

Sihombing, Daniel Romi. "Perlindungan Hukum Bagi Debitur Wanprestasi Dalam Eksekusi Jaminan Fidusia Berdasarkan Undang-Undang Nomor 42 Tahun 1999 Tentang Fidusia.” Jurnal Hukum Media Justitia Nusantara 6, no. 1 (2019).

Safitri Kusumawardani, interview by Insiyah. Pelaksanaan Jaminan Fidusia pada Pembiayaan Murabahah di Bank BNI Syariah Probolinggo (November 28, 2020).

Sukihana, Ni Wayan Indah Junyanitha I Nyoman Mudana Ida Ayu. "Pendaftaran Fidusia Dalam Praktek Pemberian Kredit Pada PT. Bank Perkreditan Rakyat Raga Jayatama Di Batubulan Gianyar.” Kertha Semaya 3, no. 2 (2015).

Tangguh Hendrawan, interview by Insiyah. Pelaksanaan Jaminan Fidusia pada Pembiayaan Murabahah di Bank BNI Syariah Probolinggo (November 29, 2020).

Winarno, Jatmiko. "Perlindungan Hukum Bagi Kreditur Pada Perjanjian Jaminan Fidusia." 
Jurnal Independent 1, no. 1 (2013).

Yuarsyah, Yopi Rama, interview by Insiyah. Pelaksanaan Jaminan Fidusia pada Pembiayaan Murabahah di Bank BNI Syariah Probolinggo (November 16, 2020).

Yani, Anggraeni. "Pelaksanaan Eksekusi Jaminan Fidusia Dalam Pembiayaan Murabahah Di Bprs Khasanah Ummat Purwokerto Pasca Putusan Mahkamah Konstitusi Nomor 18/PUU-XVII/2019." IAIN Purwokerto, 2020.

"Visi \& Misi | BNI Syariah." Accessed November 12, 2020. https://www.bnisyariah.co.id/id$\mathrm{id} /$ perusahaan/tentangbnisyariah/visimisi. 